\title{
Fatigue Properties of DLC-Coated Stainless Steel
}

\author{
Tatsuro MORITA ${ }^{* *}$, Kouta TOMITA***, Chuji KAGAYA****, \\ Tadashi KUMAKIRI $^{* * * * *}$ and Masaru IKENAGA ${ }^{* * * * *}$ \\ ** Department of Mechanical \& System Engineering, Kyoto Institute of Technology, \\ 1 Hashigami-cho, Matsugasaki, Sakyo-ku, Kyoto, 606-8585, Japan \\ E-mail: morital@kit.ac.jp \\ ${ }^{* * *}$ Former Graduate Student, Department of Mechanical \& System Engineering, \\ Kyoto Institute of Technology \\ **** Department of Mechanical Engineering, Chubu University, \\ 1200 Matsumoto-cho, Kasugai, Nagoya, 487-8501, Japan \\ E-mail: kagaya@isc.chubu.ac.jp \\ ***** Machinery and Engineering Company, Kobe Steel, Ltd., \\ 2-3-1 Shinhama, Arai-cho, Takasago, Hyogo, 676-8670, Japan \\ E-mail: kumakiri.tadashi@kobelco.com

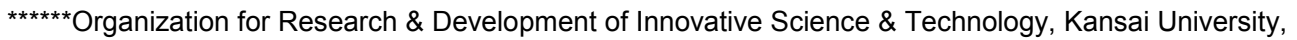 \\ 3-3-35 Yamate-cho, Suita, Osaka, 564-8680, Japan \\ E-mail: ikenaga@im.kansai-u. ac.jp
}

\begin{abstract}
This study was conducted to investigate the effect of DLC (diamond-like carbon) coating on fatigue properties of austenitic stainless steel SUS304. For the DLC coating, UBMS (unbalanced magnetron sputtering) equipment was used. The generated surface layer of about $2 \mu \mathrm{m}$ thickness was composed of both the DLC layer possessing high hardness and a very thin intermediate layer to improve adhesion force between the DLC layer and the substrate. DLC coating, which was carried out at a relatively low temperature, had no influence on the microstructure so that the mechanical properties of the stainless steel were unchanged by the coating. The results of the plane-bending fatigue test showed that the DLC coating improved fatigue strength by $18 \%$. From the results of detailed observation conducted on the fatigue fracture surface, it was suggested that the improvement in fatigue strength resulted from the suppression of fatigue crack initiation due to the surface layer, which had high adhesion force and strength.
\end{abstract}

Key words: Coating Material, Surface Improvement, Fatigue, DLC Coating, Austenitic Stainless Steel, SUS 304, Adhesion, Hardness, Mechanical Properties, Fatigue Strength

\section{Introduction}

High-wear resistance and low-friction coefficient are required for machine parts in order to improve both the performance and energy efficiency of machine products. Surface modification is an effective method to improve the above wear characteristics of metals. Recently, many investigations have been actively conducted on wear characteristics, adhesion force and residual stress of surface layers formed by surface-modification methods such as PVD (physical vapor deposition) and CVD (chemical vapor deposition) methods ${ }^{(1)-(8)}$. In a variety of PVD methods, DLC (diamond-like carbon) coating is especially worthy of attention as a new method. It has already been shown by some studies that this coating

*Received 12 Feb., 2008 (No. T1-06-0427) Japanese Original : Trans. Jpn. Soc. Mech. Eng., Vol.72, No.722, A (2006), pp.1550-1555 (Received 19 Apr., 2006) [DOI: 10.1299/jmmp.2.645] 
can remarkably improve wear resistance and strikingly decrease the friction coefficient of steel and titanium alloys ${ }^{(9)-(13)}$.

On the other hand, cyclic bending stress is often applied to sliding parts of machine products. It is usually thought that the formation of surface hardened layers can improve the fatigue strength of metals as well as the wear characteristics. For example, however, it has been reported that when titanium and its alloys were gas-nitrided, fatigue strength was reduced by cracking, which was induced in the outermost brittle compound layer under cyclic stress ${ }^{(14)-(19)}$. This means that the formation of hardened layers does not always improve the fatigue strength of metals. Accordingly, we should investigate the fatigue properties of DLC-coated metals in detail to secure the safety of machine parts.

In this study, we investigated the fatigue properties of DLC-coated austenitic stainless steel SUS304 as a model material. For the DLC coating, UBMS (unbalanced magnetron sputtering) equipment was used. After the characteristics of the DLC layer, such as hardness, Young's modulus, adhesion force, etc., were investigated, the tensile test and plane-bending fatigue test were conducted on the uncoated material and DLC-coated material. Then, the fracture surface and side surface of the tensile specimens were observed by SEM (scanning electron microscope) as well as the fatigue crack initiation sites.

\section{Materials and Experimental Procedure}

Table 1 shows the chemical composition of the austenitic stainless steel SUS304 used as the starting material in this study. To homogenize the microstructure, the stainless steel was solution-treated for $1.2 \mathrm{ks}$ at $1373 \mathrm{~K}$ and water-quenched, and then it was machined to the three specimen configurations shown in Fig. 1(a)-(c).

Table 1 Chemical composition of stainless steel SUS304 (wt \%).

\begin{tabular}{cccccccc}
\hline $\mathrm{C}$ & $\mathrm{Si}$ & $\mathrm{Mn}$ & $\mathrm{P}$ & $\mathrm{S}$ & $\mathrm{Ni}$ & $\mathrm{Cr}$ & $\mathrm{Fe}$ \\
0.06 & 0.35 & 1.68 & 0.034 & 0.027 & 8.30 & 18.7 & Bal.
\end{tabular}

(a)
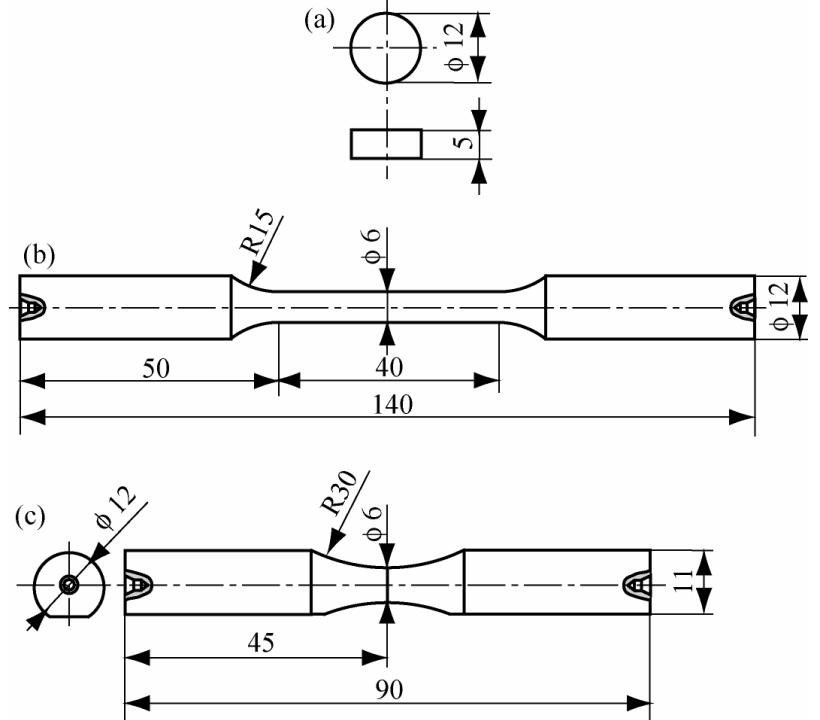

Fig.1 Configurations of the specimens $(\mathrm{mm})$ for: (a) observation and various measurements; (b) tensile test (JIS No.14); (c) fatigue test (JIS No.2).

For the button-type specimens shown in Fig. 1(a), the test section was polished to a mirror surface with emery papers (\#100-\#2,000) and alumina powders $(\# 3,000, \# 10,000)$. After DLC coating, these specimens were used to obtain the characteristics of the DLC layer such as the thickness, surface roughness, hardness, Young's modulus and adhesion 
force. For the tensile specimens and fatigue specimens shown in Fig. 1(b) and (c), their test sections were polished with emery papers and electro-polished to a mirror surface, and then DLC-coated. For comparison, we also prepared uncoated specimens which were polished in the same way.

DLC coating was conducted for all specimens at the same time, using UBMS equipment. The specimens were pre-heated for $1.8 \mathrm{ks}$ at $773 \mathrm{~K}$ in a vacuum of $2.6 \times 10^{-3} \mathrm{~Pa}$, and then their surface was cleaned up by argon impingement. After an intermediate layer was formed, the DLC layer was generated for $16.8 \mathrm{ks}$. In addition, a standard sample (JIS SKH 51 steel) was DLC-coated together with the above specimens. This sample was used to check the condition of the DLC layer by measuring its hardness and adhesion force.

Observation of the surface layer was carried out on cross-sections, using a optical microscope. For the uncoated material and DLC-coated material, their microstructure in the substrate was observed after electrolytic etching with $10 \%$ oxalic acid in order to reveal the grain boundaries. Thickness of the formed layer, including the intermediate layer, was measured by the Callot test. Hardness and Young's modulus of the DLC layer were measured 15 times using a nano-indenter, and their average values were used as the experimental values, respectively. Adhesion force of the DLC layer was obtained through a scratch test. Furthermore, hardness distributions from the surface to the inside were obtained for the uncoated material and DLC-coated material, using a micro-Vicker's hardness tester under the test force of $490 \mathrm{mN}$. In this test, hardness was measured 5 times at each depth and the hardness at each depth was obtained as their average value.

The tensile test was conducted using a universal testing machine for the uncoated material and DLC-coated material. In this test, we measured strain using a strain gauge while increasing the test force in steps. For the tensile test, three specimens were used for each material. After testing, the tensile fracture surface and side surface near the fracture region were observed by SEM (scanning electron microscope). The plane-bending fatigue test was carried out under the conditions of stress ratio $R=-1$, frequency of $20 \mathrm{~Hz}$ in air at room temperature. To investigate the behavior of fatigue crack initiation and propagation, we observed the surface of test sections using a light microscope before fracturing the specimens, and then observed crack initiation sites on the fracture surface in detail using SEM.

\section{Experimental Results and Discussion}

\subsection{Surface Layer and Microstructure in Substrate}

Figure 2 shows the surface layer observed on the cross-section of the DLC-coated material. Table 2 shows the basic characteristics of the surface layer such as its thickness, hardness and adhesion force. In addition, the thickness of the surface layer was the value measured by the Callot test and included the thickness of the intermediate layer

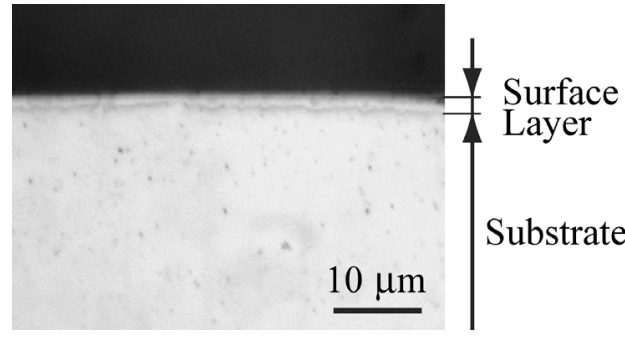

Fig.2 Feature of the surface layer. under the DLC layer.

It was understood from Fig. 2 that a surface layer formed on the DLC-coated material and its thickness was about $2 \mu \mathrm{m}$. This thickness was almost the same as the value measured by the Callot test, as shown in Table 2. The Young's modulus of the DLC layer was 1.9 times as high as that of SUS304 steel (see Table 3) and it was also very hard. The adhesion force of the DLC layer was lower than the value of the standard sample whose substrate was SKD 51 steel $(90 \mathrm{~N})$; however, even if the substrate was stainless steel, the 
DLC layer fully adhered to the substrate through the intermediate layer and it did not peel off during the tensile test (Fig. 5).

Figure 3 shows the hardness distribution measured from the surface to the inside. As shown in the figure, there was a hardened layer reaching $50 \mu \mathrm{m}$ depth and the hardness gradually decreased toward the inside to the value of the substrate. This hardened layer could result from strain-hardening occurring while polishing the specimen surface, or the diffusion of either carbon in the DLC layer or elements composing the intermediate layer. However, since the reason was not clarified in this research, more detailed investigations are needed on this point.

Table 2 Fundamental characteristics of the DLC layer.

\begin{tabular}{ccccc}
\hline $\begin{array}{c}\text { Thickness } \\
(\mu \mathrm{m})\end{array}$ & $\begin{array}{c}\text { Surface } \\
\text { Roughness } \\
(\mathrm{nm})\end{array}$ & $\begin{array}{c}\text { Young's } \\
\text { Modulus } \\
(\mathrm{GPa})\end{array}$ & $\begin{array}{c}\text { Hardness } \\
(\mathrm{GPa})\end{array}$ & $\begin{array}{c}\text { Adhesion } \\
(\mathrm{N})\end{array}$ \\
\hline $1.9 *$ & $\begin{array}{c}\mathrm{R}_{\mathrm{a}}=4 \\
\mathrm{R}_{\max }=500\end{array}$ & 365 & 59.3 & 25 \\
\hline \multicolumn{5}{c}{ *including the intermidiate layer } \\
\end{tabular}

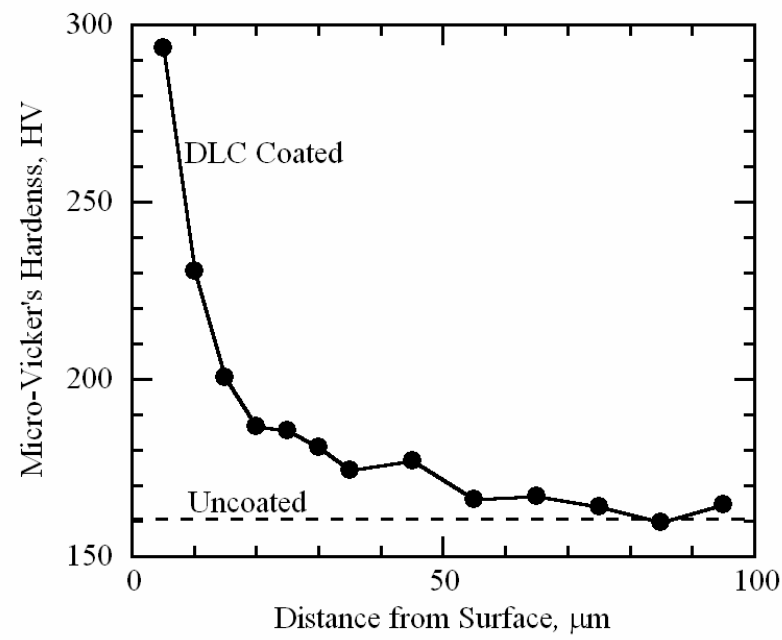

Fig.3 Hardness distribution of the DLC-coated material measured on the cross-section from the surface to the inside.

(a)

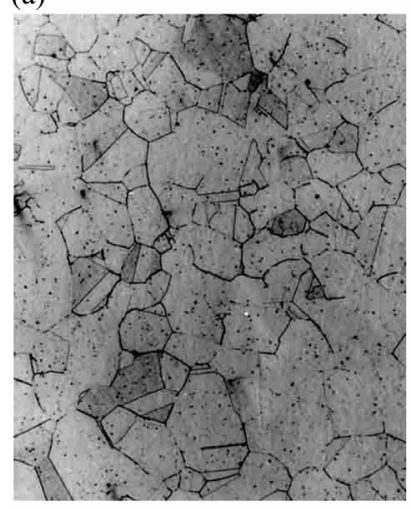

$100 \mu \mathrm{m}$ (b)

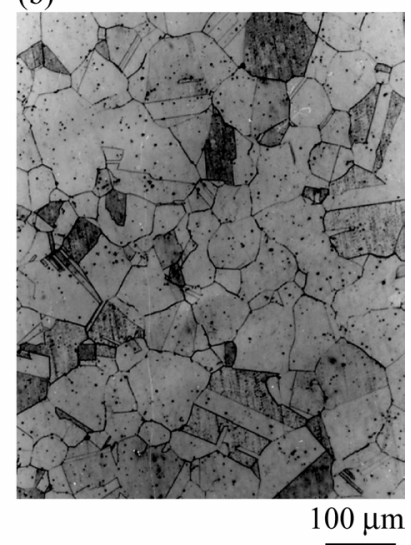

Fig.4 Microstructures observed in the substrate: (a) uncoated material; (b) DLC-coated material. 
Figure 4 shows the microstructure of the uncoated material and DLC-coated material observed on the cross-section. Comparing the features of the microstructure in the substrate, we could find no remarkable difference between them. In addition, their grain size was almost the same, as shown in Table 3. As mentioned above, the DLC coating did not affect the microstructure of the stainless steel because it was conducted at a relatively low temperature.

\subsection{Mechanical Properties}

Table 3 shows the mechanical properties of the uncoated material and DLC-coated material. In this table, their grain size is shown together. Figure 5 shows the results of observations carried out on the side surface near the fracture regions of the DLC-coated material after the tensile test. Further, Fig. 6 shows feature of the tensile fracture surface observed near the surface and its center.

Table 3 Mechanical properties and grain size.

\begin{tabular}{ccccccc}
\hline \multicolumn{4}{c}{ Young's } & \multicolumn{2}{c}{ Yield } & Tensile \\
& $(\mathrm{GPa})$ & $(\mathrm{MPa})$ & $(\mathrm{MPa})$ & $\begin{array}{c}\text { Elongation } \\
(\%)\end{array}$ & $\begin{array}{c}\text { Reduction Grain } \\
\text { of Area } \\
(\%)\end{array}$ & $\begin{array}{c}\text { Size } \\
(\mu \mathrm{m})\end{array}$ \\
\hline Uncoated & 188 & 244 & 598 & 68 & 78 & 58 \\
DLC Coated & 195 & 238 & 591 & 70 & 77 & 56 \\
\hline
\end{tabular}

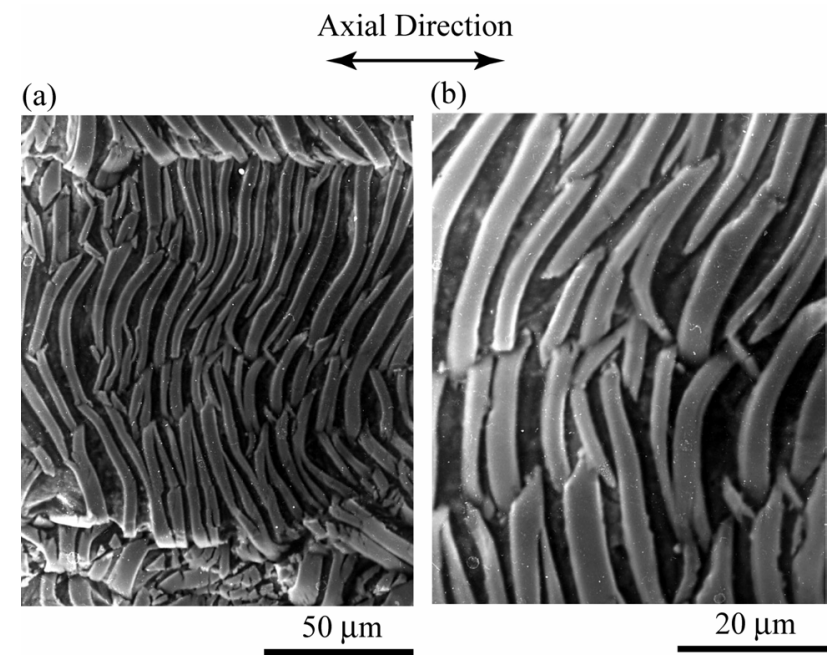

Fig.5 (a) Side feature of the DLC-coated material after the tensile test, (b) enlarged area.

In Fig. 5, we can see that the surface layer of the DLC-coated material cracked in the vertical direction against the specimen axis and the layer broke up into fine pieces; however, the surface layer did not peel off because the intermediate layer suitably adjusted for the difference in deformation between the DLC layer and the substrate through its plastic deformation. This result means that the DLC layer had high adhesion force against the substrate. Since such cracks did not propagate inside, the fracture surface of the DLC-coated material revealed a ductile feature with many dimples, and the same as the fracture feature of the untreated material.

As mentioned above, although the surface layer of the DLC-coated material cracked during the tensile test, the formation of such cracks had no influence on the fracture feature of the stainless steel. In addition, there was no change in the microstructure by DLC coating, as explained in the previous section. Accordingly, the yield stress and tensile strength of the DLC-coated material were almost the same as those of the untreated material, as understood from Table 3. Furthermore, there was no difference in the 
elongation and reduction in area between the materials. From the above results, it was confirmed that the DLC coating did not deteriorate the mechanical properties of the stainless steel.

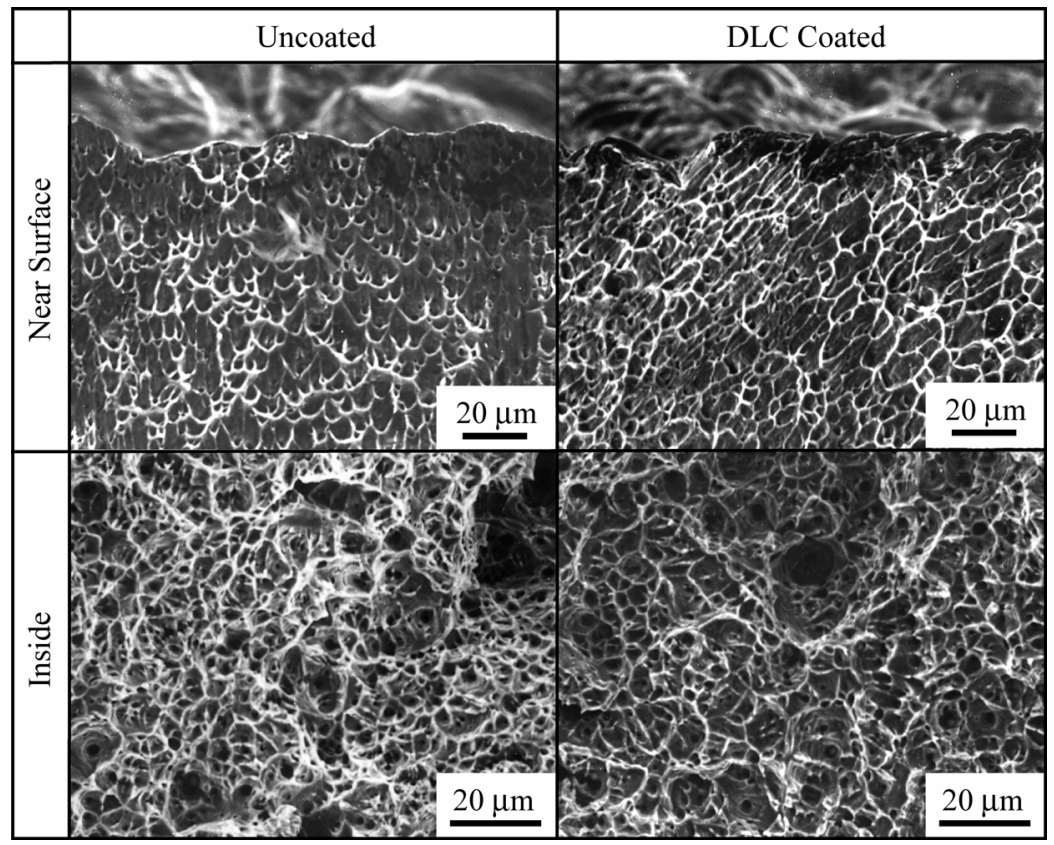

Fig.6 Feature of tensile fracture surface.

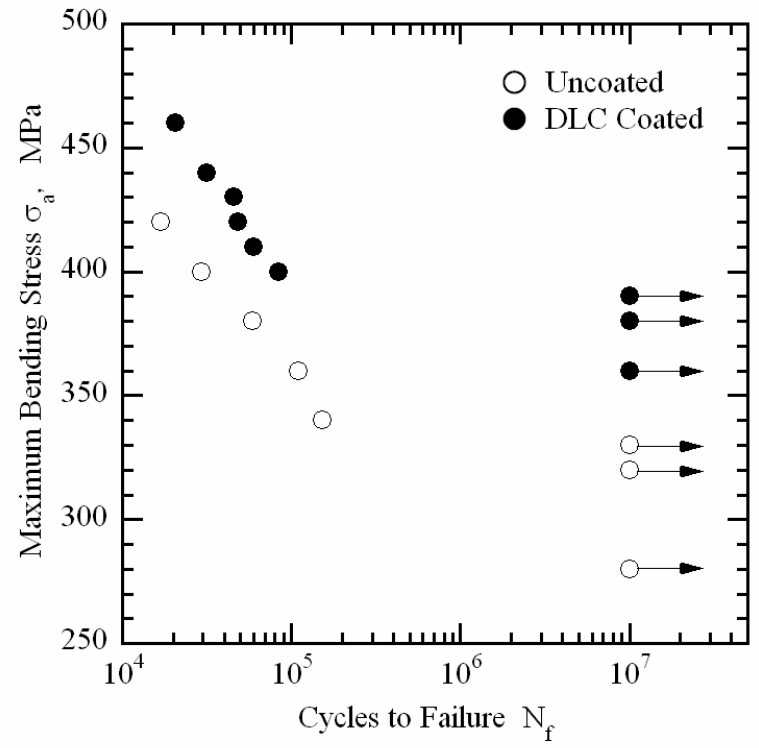

Fig.7 S-N curves.

\subsection{Fatigue Properties}

Figure 7 shows the S-N curves of the untreated material and DLC-coated material. Figure 8 shows their fatigue crack features before fracture and the fracture surface at the same positions.

From Fig. 7, it can be seen that there was very little scattering of fatigue life in both materials. This means that the solution treatment as pre-treatment and the following DLC coating were suitably conducted for all fatigue specimens. As clearly understood from the 
figure, the fatigue strength of the stainless steel as well as the fatigue life was improved by the DLC-coating so that the S-N curve of the DLC-coated material was above that of the uncoated material. In addition, the improvement of fatigue strength with DLC-coating was about $18 \%$.

On the other hand, when we observed in detail the surface of specimens which survived until $10^{7}$ cycles without fracture, no non-propagating crack was found in each material. This suggested that their fatigue strengths would be decided by the stress amplitude level in which cracks were initiated. As understood from Fig. 8, the fatigue fracture surface of the uncoated material showed that cracks initiated from the surface. In case of DLC-coated material, its fracture surface revealed that fatigue cracks initiated in the surface layer or just under it, and then cracks propagated inside in a radial pattern. Furthermore, since no feature of the surface layer peeling off the substrate was found on the fracture surface, it can be seen that the adhesion force of the DLC layer was maintained until fatigue fracture occurred under the applied cyclic stress.

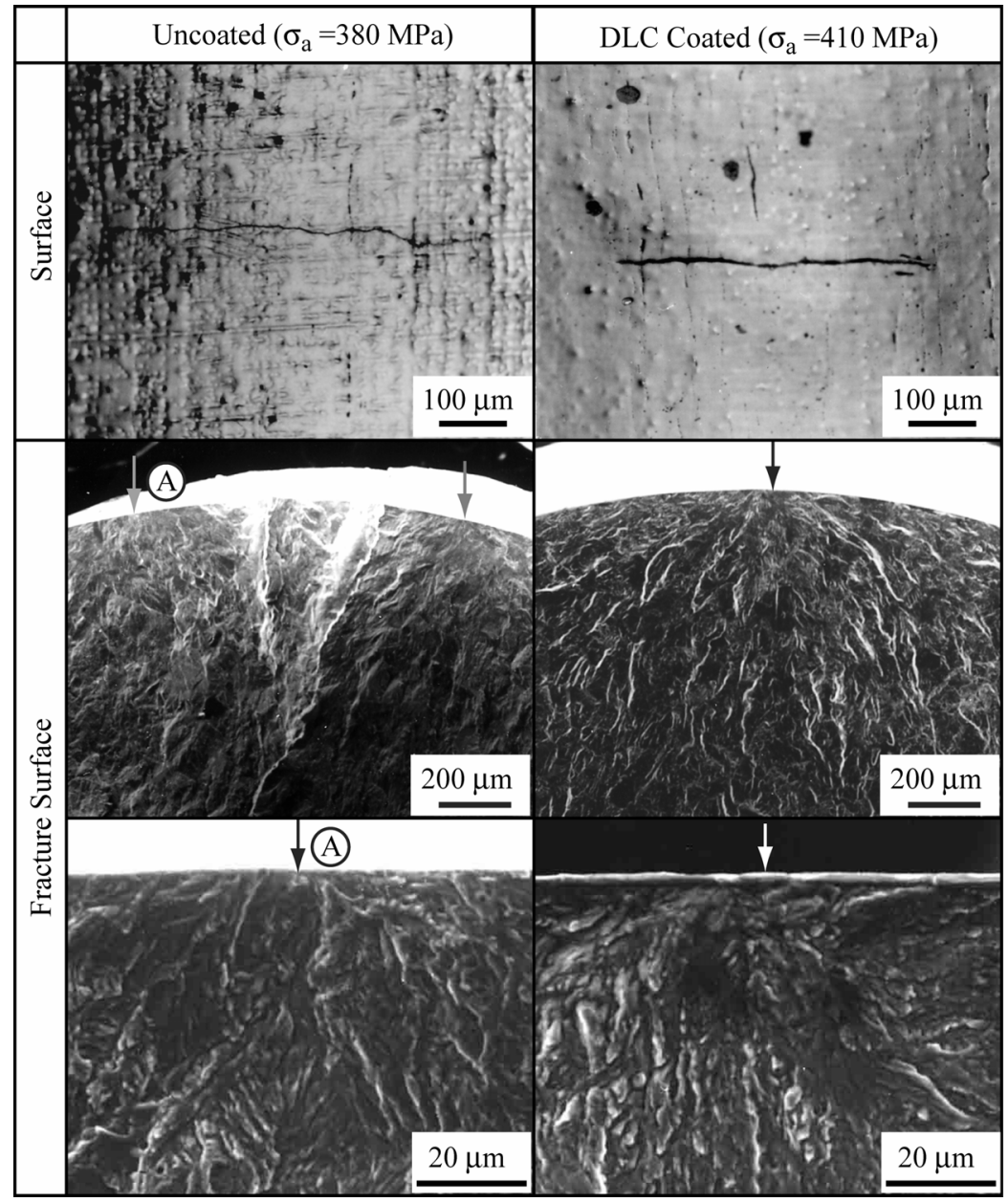

Fig.8 Feature of fatigue crack initiation sites.

As described in section 3.1, the Young's modulus of the DLC layer was 1.9 times higher than that of the substrate. In this case, high stress must be applied to the DLC layer in the situation in which the DLC layer did not peel off and strain was continuous through the interface between the layer and the substrate ${ }^{(17)-(22)}$. Further, the DLC layer was very hard so it could cause brittle fracture; however, we found neither brittle fracture of the DLC layer nor the feature of cracks preferentially propagating along the layer on the fatigue fracture surface, as mentioned above. From those facts, it can be concluded that the DLC 
layer had high strength and strongly adhered to the substrate through the intermediate layer so that fatigue strength of the stainless steel was improved by the suppression of fatigue crack initiation from the surface to a higher cyclic stress level.

It should be further noted that formation of the hardened layer under the surface layer (Fig. 3) could contribute to the improvement in fatigue strength because such a hardened layer can suppress slippage occurring in the substrate and reduce its influence on the surface layer, although it was not clarified why the hardened layer formed. In addition, the effect of residual stress generated in the DLC layer was not examined in the present research. Such examination is needed to consider surface layer fracture in detail.

\section{Conclusions}

(1) When stainless steel SUS 304 was DLC-coated by UBMS equipment, the formed DLC layer possessed Young's modulus, which was 1.9 times higher than that of the substrate and was very hard. The DLC layer strongly adhered to the substrate through a very thin intermediate layer.

(2) There was no difference in the microstructure and grain size of the substrate between the uncoated material and DLC-coated material. This result showed that DLC coating had no influence on the microstructure of stainless steel.

(3) The yield stress and tensile strength of the DLC-coated material were almost the same as those of the uncoated material. Also, their reduction in area and elongation were about the same, meaning that DLC coating at a relatively low temperature had no influence on the mechanical properties of the stainless steel.

(4) The fatigue strength of the stainless steel improved by $18 \%$ with DLC coating. From the results of observation of the fatigue fracture surface, it was suggested that fatigue crack initiation from the surface was suppressed by the existence of DLC layer so that fatigue strength of the stainless steel was improved.

(5) From the detailed experiments conducted in this study, it was clearly shown that the fatigue strength of the stainless steel was improved without the deterioration of the mechanical properties by DLC-coating, which can improve wear properties such as wear resistance and the friction coefficient.

\section{References}

(1) Martinella, R. et al., Wear Behavior of Nitrogen-implanted and Nitrided Ti-6Al-4V Alloy, Materials Science \& Engineering, Vol.69 (1985), pp.247-252.

(2) Shimomura, J. et al., Formation of TiN Film on High Carbon-High Chromium Steel by Ion Beam Implanted Vapor Deposition (IVD) and Its Wear Resistance, Journal of the Surface Finishing Society of Japan, Vol.39, No.10 (1988), pp.630-635.

(3) Saritas, S. et al., The Use of Ion Implantation to Modify the Tribological Properties of Ti-6Al-4V Alloy, Materials Science \& Engineering, Vol.90 (1990), pp.297-306.

(4) Blawert, C., Plasma Immersion Ion Implantation: Innovative Technology for Surface Treatment of Stainless Steel, Surface Engineering, Vol.15, No.2 (1999), pp.154-158.

(5) Fu, Y. et al., Some Considerations on the Mitigation of Fretting Damage by the Application of Surface-Modification Technologies, Journal of Materials Processing Technology, Vol.99 (2000), pp. 231-245.

(6) Tosa, M. et al., Adherence of TiC Films on SUS304 and SUS321 Stainless Steels, Journal of the Surface Science Society of Japan, Vol.5, No.2 (1984), pp.136-142.

(7) Yamamoto, T. et al., An X-ray Study of Residual Stress Generated in Carbide Coated with TiN by CVD Process and PVD Process, Journal of the Japan Institute of Metals, Vol.50, No.3 (1985), pp.120-127. 
(8) Saito, K. et al., Microstructures of Ti Ion Implanted Fe and Fe-Base Alloy Surfaces and Their Adhesion to TiC Coating Films, Journal of the Japan Institute of Metals, Vol.53, No.4 (1989), pp.393-398.

(9) Cellier, F., Nowak, J.F., Diamond-Like Carbon Film Deposition on Plasma Nitrided Steel Substrate, Diamond \& Related Materials, Vol.3 (1994), pp.1112-1116.

(10) Rosado, L. et al., The Effect of Diamond-Like Carbon Coatings on the Rolling Fatigue and Wear of M50 Steel, Wear, Vol.212 (1997), pp.1-6.

(11) Strondl, C. et al., Properties and Characterization of Multilayers of Carbides and Diamond-Like Carbon, Surface \& Coatings Technology, Vol. 142-144 (2001), pp.707-713.

(12) Schiffmann, K.I., Phenomena in Microwear Experiments on Metal-Free and Metal-Containing Diamond-Like Carbon Coatings: Friction, Wear, Fatigue and Plastic Deformation, Surface\& Coatings Technology, Vol.177-178, (2004), pp.453-458.

(13) Corbella, C. et al., Time-Resolved Electrical Measurements of a Pulsed-DC Methane Discharge Used in Diamond-Like Carbon Films Production, Thin Solid Films, Vol.482 (2005), pp.172-176.

(14) Mitchell, E., Brotherton, P.J., Surface Treatments for Improving the Wear-Resistance and Friction Properties of Titanium and Its Alloy, Journal the Institute of Metals, Vol.93 (1964-65), pp.381-386.

(15) Bell, T. et al., Surface Engineering of Titanium with Nitrogen, Surface Engineering, Vol.2, No.2 (1988), pp.133- 143.

(16) Shibata, H. et al., Effect of Gas Nitriding on Fatigue Behavior of Ti-15Mo-5Zr-3Al Alloy, Transactions of the Japan Society of Mechanical Engineers, Series A, Vol.59, No.564 (1993), pp.1795-1799.

(17) Morita, T. et al., Fatigue Property of Nitrided Ti-6Al-4V Alloy, Transactions of the Japan Society of Mechanical Engineers, Series A, Vol.56, No.529, (1990), pp.1915-1919.

(18) Morita, T. et al., Factors Controlling the Fatigue Strength of Nitirided Titanium, Fatigue \& Fracture of Engineering Materials \& Structures, Vol.20, No.1 (1997), pp.85-92.

(19) Morita, T. et al., Fatigue Strength of Nitrided High-Strength Titanium Alloy, Ti-2003 Science and Technology, Vol.II (2004), pp.941-948.

(20) Morita, T. et al., Analysis of Stress Field Generated in Thin-Layer by Pile-up of Screw Dislocations, Theoretical and Applied Mechanics, Vol.44 (1995), pp.137-144.

(21) Morita T., Tanaka, Y., Behavior of Dislocations in a Surface-Layer/Substrate Elastic System, Theoretical and Applied Mechanics, Vol.53 (2004), pp.19- 26.

(22) Hashimoto, M. et al., An-X-ray Study on Residual Stress and Fatigue Characteristics of TiC Coated Steel, Journal of the Society of Materials Science, Japan, Vol.39, No.437 (1989), pp.150-156. 